Dinesh Bhugrai*

\title{
Dinesh Bhugra: a personal history of Psychiatry
}

\author{
'Emeritus Professor Mental Health \& Cultural Diversity, IoPPN, Kings College, London SE5 8AF \\ *email: Dinesh.Bhugraakcl.ac.uk
}

DOI: 10.2478/gp-2019-0003

Received: 13 December 2018; Accepted: 13 December 2018

\begin{abstract}
In the past 40 years, the practice of psychiatry has changed dramatically from asylums to community care to personalized homebased treatments. The personal history of working in various settings and changing NHS indicates that an ability to change one's clinical practice is a critical skill. Being a migrant and an International Medical Graduate brings with it certain specific challenges. Personal histories provide a very specific account that is inherently incomplete and perhaps biased, but personal accounts also give history a tinge that academic accounts cannot. In this account, changes in the NHS have been discussed with regards to changes in clinical care of patients with psychiatric disorders as well as research and training.
\end{abstract}

\section{Keywords}

History, NHS, management, asylums, psychotherapy.

\section{A PERSONAL HISTORY OF PSYCHIATRY}

In 1947, when India was partitioned, and the British left the subcontinent, millions of people had to face forced migration and move across the borders-Hindus moving from largely Muslim Pakistan (both East and West) and Muslims from India to Pakistan. Millions were massacred. My parents moved across to India with just the clothes on their back. I still have the certificate that my father was classified as a refugee. Although academically bright, he finished school with top grades but his parents could not afford to send him to University and he managed to find a job in a bank where he gradually progressed over the 35 years of service. My parents and grandparents never talked about what they went through, though my maternal grandmother let slip once that she was on the last train that reached India safely. My parents were married a year after the partition, and I recall being called a refugee in school, although I was born in free India. My migration to the United Kingdom occurred in 1978 so I am truly a second-generation migrant.

\section{BACKGROUND}

At the age of 16 years, in the final year of school, I was awarded the National Science Talent Search scholarship after a fierce national competition, which would have paid for 8 years of basic sciences training leading to a $\mathrm{PhD}$. At that time, across the whole country, only 100 scholarships were awarded annually. Both my parents were unhappy with this choice and like most migrants wanted me to join a profession. In a paradoxical injunction, I was challenged by my father that I could not get into a medical school and I responded by gaining entry to Armed Forces Medical College in Pune. For 120 seats (20 seats were reserved for women), there were more than 10,000 applicants, of whom only about 300 were interviewed after an initial screening test followed by an aptitude test. Joining Medical College where Armed Forces discipline prevailed with uniforms, parades, and training in rifle shooting was an interesting experience as was the language. English was the medium of instruction, and I had to polish my language. Another factor was the use of Marathi, which was the local language, so learning Marathi to communicate with patients was important. There were 3 parts of MBBS each with 3 terms and each part lasts for 18 months. First three terms focused largely on anatomy and physiology. I recall very vividly that in my second year, having just come out of the dissection hall, while riding my bicycle back to the hostel, I started thinking and questioning about the fact that human beings have similar anatomy and similar physiology and yet everyone is so different, which made me interested in psychiatry. In the 5-year course, there were only 2 weeks posting in psychiatry, which most students did not take seriously. I recall that the very first patient I saw was needless to say a soldier from south India. He complained that in the army, he was not given rice (his preferred option) and had gone mad because of eating chapatis. I started reading about Freud and 
others. When I expressed my interest in the field of psychiatry, everyone around me tried to discourage me. I applied to six centers in India for postgraduation was invited for only one interview and did not get a job. Whether this was due to nepotism or local factors as medical colleges often preferred their own students and as I was not planning to join the Armed Forces they did not is difficult to know. Hence, I decided to move to the United Kingdom. I took TRAB examination (predecessor to Professional and Linguistic Assessment Board [PLAB]) held by the GMC. At that time, GMC conducted the language examination and offered unpaid placements for up to 28 days to observe and gain experience and UK referees.

\section{TRAINING IN ASYLUMS}

I spent a fortnight in Northampton as an observer on a medical ward and then worked there. In 1980s, the asylums were the norms. I was selected for the rotation in Leicestershire District Training Scheme and the Academic Unit was run by two senior lecturers. It was a separate unit with active teaching. Academic teaching was in the academic department and research was left to individual trainees' interest. I was interested in research and was well supported by academics. The rest of the postings were in the two asylums. The experience was extremely valuable. The wards were large with Victorian-style dormitories and huge grounds surrounded by accommodation for the staff. This was in 1981. Griffith reforms of the NHS had just been introduced.

The doctors' quarters were separate, and every lunch time, hot trolley would be wheeled in. The meetings with consultants over lunch were exceptionally helpful, in that one could talk about problems and clinical difficulties without worrying about confidentiality and other people listening into one's conversations. The caretaker used to remind us that till recently all rooms were given fresh bowls of fruit every day. It was a house where trainees could stay for on-call or for periods of training as could medical students. Leicester Medical School had been going for only a short while and first set of graduates passed out during this period. In addition to wards being big, often patients had been there for years. An 87-year-old female patient who died in one of the wards had been there since she was 17 years old when she had got pregnant without marriage. Local GPs had contract to visit the wards every 2-3 days to carry out physical examinations and investigations if needed. The consultants were extremely supportive. I was curious about clinical cases, and not surprisingly, the clinical material in the hospital was challenging and interesting, and with senior consultants, I published several case reports (Bhugra 1985: Bhugra \& Frost 1985: Bhugra \& Kaye 1986; Bhugra \& Low 1986).
The ward rounds were multidisciplinary, and the letters to GPs were typed by the secretarial staff after dictations. The case notes were handwritten, which at times had problems in ability to understand or read the writing.

In one posting, I was allowed to keep my outpatients list for 18 months in spite of rotating to 2 other placements, which meant that I could follow-up patients for a longer time and learn from my mistakes. Weekly teaching was organized with external speakers and local lecturers. Psychotherapy training for trainees was compulsory, and informal arrangements existed among Leicester, Derby, and Nottingham for trainees to undergo therapy themselves. I spent 18 months driving to Derby every Tuesday morning and undergoing dynamic therapy. Most important lesson was learning about counter-transference and transference having experienced it first-hand.

I was fortunate to arrange to attend a psychosexual service run by a clinical psychologist on Tuesday evenings. One of the first couples I saw was a Punjabi couple who were referred by obstetricians for inability to conceive. I recall vividly that the man would insist on speaking for his wife who became more withdrawn. I brought in female psychologist who did not speak the language but her presence itself changed the dynamics in the room. It appeared that they did not have basic knowledge of the sexual act, so education helped them get over the problem. This led me to my first major paper (Bhugra \& Cordle 1986), which was accepted by the BMJ, and got me interested in cultural differences and similarities and their role in genesis and maintenance of psychiatric disorders.

When I moved to the Maudsley for my higher training, I chose to do a Masters in Sociology of Health and Illness and then a Masters in Social Anthropology.

\section{CLINICAL TRAINING}

Although there was an expectation from the Royal College of Psychiatrists that all trainees receive an hour's weekly supervision, this did not always happen; however, all consultants with whom I had the privilege to work for were excellent in their support to the trainees, and an apprenticeship model worked extremely well, which is a major change from the current shift work where trainees often do not feel that they belong to a firm and consequently feel less supported and isolated. The college tutors were very helpful, and teaching both internally and externally was excellent. Our neuroanatomy training was in Nottingham for a 1-week period. The academics encouraged me to write and conduct research. I obtained MPhil by doing a project on the attitudes of doctors to male homosexuality 
through Leicester University. This led to several publications (Bhugra 1987, 1988, 1990); I was also interested in looking at the patients' attitudes to ECT, which, to my mind and clinical experience, remains one of the most effective treatments.

The clinical experience in training included child psychiatry in Leicester and Loughborough. One of the child psychiatrists I worked for was a student at the time of the establishment of the NHS and provided a wonderful insight and she was also a trained psychoanalyst, thus adding another dimension to developmental psychiatry. I still vividly recall that I was looking after a 4-year-old child with nocturnal bed-wetting, and we worked very well and he was getting better, but when I told him and the family that I was finishing and leaving, his problem returned. Here was a major lesson in ensuring that the task of termination in therapy begins with the first session. The placements also offered opportunities to teach medical students who were indeed a very impressive bunch. The use of ECT was selective, and under the Head of the Department, Leicester carried out a study on the use and effectiveness of ECT. I was involved in a study collecting data from patients under the supervision of one of the senior lecturers looking at the use of pimozide for the treatment of monosymptomatic hypochondriacal delusions.

The wards were huge dormitories with seclusion rooms on some wards, but these often remained unoccupied. The workshop for occupational therapy was very busy and extremely successful, and patients were looked after. Interestingly, there were staff across generations among nursing staff, that is, their parents and grandparents had also worked in the asylums, which provided a wonderful insight into history of clinical practice. Interestingly, often District Rehabilitation Officers would attend the discharge meetings to help find employment opportunities and placements for patients. Around about the same time, following Griffith report, management was introduced in the NHS. The result was that doctors withdrew into clinical work and often managers were of indeterminate quality, which affected the development of services. In the name of equality, services for doctors' dining rooms were withdrawn, as these being seen as privileges. The loss of informal supervision and discussion of patients in a confidential manner did impact on training in many ways. I remember a patient vividly who was in his mid-20s with a diagnosis of schizophrenia and diabetes, who would sit in the grounds looking at the sun. On one occasion while I was driving to town, I saw him waiting at the bus stop and decided to give him a lift. Ward staff were horrified that I had done so. However, weeks later, after he had recovered, he came to see me and said that he remembered everything that I had said to him, reminding me that just because people have psychosis does not mean that they cannot remember things-a salutary lesson.

\section{HIGHER TRAINING}

After completing my MRCPsych examination in 1985, I applied to the Maudsley for Senior Registrar training and was lucky to be offered a job. My first placement was in Eastbourne at the Hellingly Hospital, which was also an asylum and was in the midst of being closed. My special interest sessions were in psychiatry of older adults, with Eastbourne having a significant population in that age group. The unusual part of the training was that I was given four beds that I ran like a consultant, although advice, support, and help were easily accessible from the consultant who was my trainer. A year later, moving to the Bethlem Royal brought me in touch with a very busy ward with four clinicians who were also academics. This placement included my working in a Mother and Baby Unitone of the first ones in the country. This led to working very closely with community psychiatric nurses and social workers. Discussions with senior colleagues were always challenging and intellectually stimulating. The role included teaching trainees, and the calibre of trainees was really superb.

At that time, the NHS ran regular courses on Management Training, and I attended my first course in 1986 in Harrogate. This triggered my interest and as Senior Registrar with colleagues to set up a week-long course in the Institute of Psychiatry, which formed the basis of our book on the topic which is now in its fourth edition (Bhugra et al 2017). Arriving in the Maudsley opened very many doors. The general atmosphere was academic, and I recall my thesis being typed on the early types of desk top computers.

After a year in Eastbourne, which was incredibly busy clinical post, Bethlem offered a mix of academic and clinical challenges. The national psychosis unit offered care and second opinions to patients from all around the country. I continued to develop my interest in psychosexual problems and used the clinic as my special interest. Home visits while on call became the norm and assessments for detention under the Mental Health Act were not uncommon. Walking up the stairs of tower blocks in the middle of the night with the duty social worker and sometimes the police was an interesting experience.

My third placement was on the inpatient psychotherapy unit, which was beginning to change its shape and function. One of the major inputs was psychotherapy at individual and group levels. The patients were presented on the ward round only after they had been on the ward for at least 4 weeks with thorough 
multiprofessional assessment, and in each ward round, only one patient would be discussed. The ward rounds often lasted for 5 hours, discussing just the one patient. After presentations by the Senior House Officer, nurses, social workers, and occupational therapist, the senior registrar will then provide a formulation after the consultant had interviewed the patient (and the carers, if they attended) for about 45 minutes, and treatment plan will be discussed and explained to the family as well. This type of in-depth discussion and training is nonexistent in the modern NHS, which is a real shame. The general principle is to bring everything down to the same minimal level.

During this period, I thought of repeating the Odegaard study, but this time looking at the rates of schizophrenia among south Asians and African-Caribbeans (Bhugra et al 1996, Bhugra et al 1997). This study continued for 3 years and led to the award of a $\mathrm{PhD}$. The study also acted as a pilot study for a further major study. I was taken off the subsequent grant application and study because the senior investigator thought that as no Asian patients were to be included, I was superfluous to the study team. I am sure that this racist view will not be tolerated these days.

\section{PARADIGMS OF TREATMENT}

During my basic training days, the role of the psychologists was largely carrying out psychometric assessments, and it was only with wide spread use of behavior and then cognitive behavior therapy that there was a major shift. Furthermore, community psychiatric nurses as a discipline only became prominent in the mid- to late-1990s after the closure of asylums and establishment of community care. In addition, the changes and the introduction of the 1983 Mental Health Act contributed to changes in the role of social workers. Current practice of psychiatry is a mixture of different modalities of treatments, and access to information from bulky books including British National Formulary is now in one's mobile phone or laptop. The introduction of Psychiatric Intensive Care Units was also relatively recent and rapid tranquilization protocols started to emerge. The use of clozapine changed the clinical management of patients who may have been classified as treatment resistant. This meant that more patients could be discharged to the community accommodation supported at different levels.

\section{CONSULTANT ROLE}

In 1992, I took over the running of a community mental health team in Camberwell in the same building where a specialized service for African Caribbean patients was piloted for 3 years funded by the Department of Health. I recall a significant proportion of the patients were BAME patients. The services were markedly different from my Leicester experience, in that a vast majority of patients on the ward were patients with psychosis. Looking back at that period, GPs would often attend discharge meetings. After 2 years, I was asked to lead the community rehabilitation team in Nunhead, which was a model of its kind. We would assess and follow up patients in hostels and often see them in restaurants and cafes. The approach in the team was holistic, and we would encourage the use of complementary therapies such as acupunctures and aromatherapies. If needed, patients would be admitted for short breaks and asylum in the true sense of the word. The hospital had access to crisis homes especially for women. For the 5 years, we looked after a number of patients with complex needs and multiple comorbidities. The nurse-to-patient ratio was excellent, but the managers decided to close the service because it was seen as expensive in an economic evaluation.

I then ran the intensive care unit for a couple of years. This was an interesting change, in that again a vast majority of patients were BAME and at least one patient had been on the ward for almost a year, and it took a lot of effort in moving them to a rehabilitation unit. One advantage of being in the Maudsley Hospital was that there were some excellent third sector organizations around. Camberwell Rehabilitation Association ran a sheltered employment run by a nurse and occupational therapist who managed to engage a significant number of patients before gaining full employment. The hospital had a fruit and vegetable shop called Going Bananas and a café run by patients. Inevitably, those who were good would get jobs elsewhere, and it was a constant effort to keep training patients. In 2004, I moved on to run the psychosexual and couple therapy service, which was a thoroughly enjoyable experience as no two patients were alike. In addition, you never knew who and what was coming through the door. With changes in funding, there was a major squeeze on these services.

\section{RESEARCH AND EDUCATION}

Although I had always been interested in research and publication, especially on patients' attitudes and experiences, an opportunity arose in my final year of clinical training. I took on the role of developing cultural identity tools and collecting data on differences in rates of schizophrenia and of self-harm focusing on Asian experiences in particular. Although African Caribbean and south Asian migrants came at the same time, their journeys and acculturation have been very different. This led to creating training for professionals as well as patients on understanding migration and mental illness. With the help of the hospital chaplain, training programs for black church 
leaders were developed and delivered. I prepared educational leaflets for south Asians, which was translated into several south Asian languages, on identifying and managing depression and suicidal thoughts.

My passion throughout my working life has been patient care and teaching. I developed courses for medical students and others on cinema and psychiatry, leadership skills, and cultural psychiatry.

\section{MEDICAL POLITICS}

The third stream in my career was getting involved in medical politics, which came about purely by chance. While in Leicester, I became involved in the Royal College of Psychiatrists as a trainee representative on the Collegiate Training Committee simply because, that year, there were no nominations from trainees at Senior House level from the Trent Division. This led to becoming increasingly involved in Joint Committee for higher psychiatric training, Overseas Doctors Training Committee, and then becoming chair of Faculty of Adult and Community psychiatry. During my tenure as Chair of Overseas Doctors Training Committee, I came across the stresses that International Medical Graduates go through because of a lack of induction and most of the complaints were largely due to problems in team working, so I persuaded the college to set up regular induction days educating new arrivals to learn about team working and structures of the NHS and inspire of occasional experience of racism; I managed to become its dean and then elected unopposed as a president. In the history of the college, this has never happened before or since. During this 3-year term, I set up a number of initiatives setting up awards recognizing achievements and contributions of clinicians, academics, and patients and projects to help understand issues related to migrant mental health. I led on the development of various policy documents and reports (Bhugra 1995, 2010a,b, Bhugra et al 1995). I set up evening lectures, one of which led to a round table discussion on psychiatry's social contract and appeared as a book (Bhugra et al 2010).

In 2011, I was elected as President-elect of the World Psychiatric Association-first ever British/Asian to do so. Between 2011 and 2014 as Chair of the Board of Trustees of the Mental Health Foundation, I led on psychiatry's contract with society and with Lord Carlile co-chaired a commission looking at the Future of Mental Health services collecting evidence from more than 1500 written responses and more than 50 interviews of key stakeholders in sharing the vision about how psychiatric services of the future should look like (Carlile \& Bhugra 2013, Bhugra 2014).
As President of the World Psychiatric Association, I set up a series of working groups looking at developing public mental health programs related to domestic gender-based interpersonal violence; child sexual, physical, and emotional abuse; prisoner mental health care; and underserved populations such as migrants, LGBT, elderly, and those with intellectual disability. Each group was tasked with producing materials for undergraduates, postgraduates, continuing medical education, and policy implications. Furthermore, I shaped and crafted 21 position statements on various topics, which have been used worldwide to shape policy. For mental health promotion, I appointed Global Goodwill Ambassadors, set up WPA Collaborating Centres, and led on a global survey of discrimination against people with mental illness showing that only about $36 \%$ of countries allow individuals with mental illness to vote, marry, inherit property, or have employment rights. I created a Bill of Rights that has been supported by 61 national and international organizations (Bhugra 2016). Further Bills of Rights for children and young people and those with intellectual disability followed. This was followed by a series of round tables around the globe on migrant mental health and a survey of Commonwealth countries looking at discrimination.

For the European Psychiatric Association, I crafted several position statements (Campion et al 2012, Bhugra et al 2015a,b, Schoular-Ocakl et al 2015), which covered a wide range of topics. As President of the World Psychiatric Association, I led on developing a WPA-Lancet Commission (Bhugra et al 2017), which made recommendations for future practice of psychiatry.

In 2017, I was elected as a President-elect of the British Medical Association and took up the post in June 2018. In this role, I influenced BMA into carrying out a survey of mental health and well-being of medical students and doctors-the findings are being analyzed currently. BMA also launched a campaign against health inequalities.

\section{FUTURE OF PSYCHIATRY}

Of all the medical specialities, to my mind, psychiatry is the most exciting, intellectually stimulating, and challenging. Why? Where else can one combine biological or medical model with social factors and causation including cultural factors, psychological aspects of functioning, and spiritual factors. I went into psychiatry with a sense of burning enquiry and that has stayed with me. Dealing with injustice, speaking up for patients, and advocating for services are key responsibilities that every doctor needs to take on. 
Looking back at the past does not mean that the past was glorious, it certainly had its problems but the changes have not been always for the best even though newer treatments and interventions have made clinical psychiatry exciting. There is no doubt that the NHS is being gradually strangled by increased command and control through increased and bureaucratic managerialism with jargon and everincreasing paperwork. Coupled with increasing demands and expectations and, in reality, reduced funding has added further problems. While in the past, the Colleges carried out inspection visits to training schemes to enable and facilitate changes, now with the regulators, it has become a cumbersome exercise (with anecdotal evidence of more than 200 inspectors visiting hospitals for up to 2 weeks) that does not necessarily encourage innovation and thinking out of the box. It feels like everything is being dragged down to the lowest possible denominator. Doctors as a profession have to speak up and be advocates for services and patients.

Psychiatry is currently at a very exciting point with our understanding of brain and its structures and functioning improving day by day. In addition, developments such as the use of social media, e-Mental health, and psychopharmacogenomics are creating new opportunities in diagnosing and managing individuals with mental illness. Social factors such as globalization and urbanization are changing and will continue to change the way individuals understand and present with emotional distress. Psychological changes related to therapies without therapists also influence interventions. We are becoming more aware and conscious of the impact that cultures have on individual development and presentations. As in the rest of medicine, patient expectations of doctors and therapy are changing. Often patients gather information from the internet about their illness and its management.

Nowadays, psychiatrists work across a whole range of placesfrom the street (literally, in providing services for homeless individuals) to community mental health teams or leading specialized teams such as early intervention, home treatment, and crisis resolution or in specialist hospital or general hospital units. However, most teams will work in both inpatient units and in community mental health teams or out-patient departments or in primary care setting, which has been a major shift in the past 40 years. Psychiatrists continue to work in teams. Teams include nurses, community psychiatric nurses, social workers, psychologists, and occupational therapists and occasionally pharmacists, physiotherapists, counselors, etc. which at times has created professional envy, tensions, and conflict. In some settings, culture brokers or culture mediators may be involved.
Medical leadership is one of the core skills, and doctors by virtue of their training already possess certain leadership skills. This training allows us to develop and use these skills while working with teams. As psychiatrists, our understanding of interpersonal relationships and group dynamics can be very helpful in developing and delivering leadership in any healthcare system. It is important that doctors learn how to advocate both as a professional and also as members of the community and society.

Leadership and management are often confused as being the same thing. They are remarkably different practices and require different sets of theory and practical skills. Sometimes there is an overlap between leadership and management, but by and large, they are very different skills. There is no doubt that increased levels of management and regulation have started to strangle parts of the health services meeting the law of unintended consequences. Key components of leadership particularly at organizational levels include vision, passion, courage, and good communication skills in carrying team members and others with that vision. Leadership skills are a must for service planning, delivery, and evaluation of the services including actual therapeutic encounters to ensure that services are effective and efficacious. Our training, expertise, and experience give us insight into leadership responsibilities. Various cultural and demographic factors such as gender, age, sexual orientation, ethnicity, and culture of places where we trained and where we work mold the way we see the world. This "world view" allows us to develop strategies that we use in dealing with patients and with other stakeholders. One of the major strengths of being a clinician or a leader is understanding our personal strengths and prejudices, which enable us to manage our patients more effectively.

Various social, political, and economic challenges are related to service delivery, development, and evaluation, and clinicians must be aware of these. The future of psychiatry is exciting. I have enjoyed my time in psychiatry, and it is heartening to see that recruitment is appearing to shift in favor of psychiatry. 


\section{REFERENCES}

Bhugra D (1985): Kartagener's syndrome. British Journal of Clinical Practice39 (1): 38-39.

Bhugra D (1987): Homophobia: a review of the literature. Sexual and Marital Therapy 2 (2): 169-177.

Bhugra D (1988): Homosexuals' attitudes to male homosexuality: a survey. Sexual and Marital Therapy 3 (2): 197-20

Bhugra D (1990): Doctors' attitudes to male homosexuality: a survey. Sexual and Marital Therapy 5 (2): 167-174.

Bhugra D (1992): Homelessness and Mental Health. London: Royal College of Psychiatrists. (CR13).

Bhugra D (2010 a): There is no health without Public mental health London: RCPsych

Bhugra D (2010 b): Roles and responsibilities of a consultant psychiatrist. London: RCPsych

Bhugra D (2014): Psychiatry's Social Contract. London: Mental Health Foundation

Bhugra D (2016): Social Justice. International Review of Psychiatry, 28,341

Bhugra D, Bridges K, Thompson C (1995): Caring for a Community. London: Gaskell.

BhugraD, Burns A (eds) (1992): Management Training for Psychiatrists. London: Gaskell $\left(2^{\text {nd }}\right.$ ed as Management for Psychiatrists 1995, $3^{\text {rd }}$ edition Bhugra D, Bell S, Burns A (eds) in 2007 and $^{\text {th }}$ edition published in 2016.London: RCPsych Publications

Bhugra D, Cordle C (1986): Sexual dysfunction in Asian couples. British Medical Journal 292 (6513): 111-112.

Bhugra D, Frost S (1985): Kallman's Syndrome. British Journal of Sexual Medicine 12 (1): 20-21.

Bhugra D, Hilwig M, Hossein B et al (1996): First-contact incidence rates of schizophrenia in Trinidad and one-year follow-up. British Journal of Psychiatry169 (5): 587-592.

Bhugra D, Leff J, Mallett R, Der G, Corridan B \& Rudge S (1997): Incidence and outcome of schizophrenia in Whites, African-
Caribbeans and Asians in London. Psychological Medicine27 (4): 791-798.

Bhugra D, Kaye N (1986): Phenelzine-induced epilepsy. British Journal of Clinical Practice 40 (4): 173-174.

Bhugra D, Low N (1986): Neuroleptic Malignant Syndrome. British Journal of Clinical Practice $\mathbf{4 0}$ (10): 445-446.

Bhugra D, Malik A, Ikkos G (2010 c): Psychiatry's Contract with Society. Oxford: Oxford University Press.

Bhugra D, Sartorius N, Fiorillo A, Evans-Lacko S, Ventriglio A, Hermans HMH, Vallon P, Dales J, Racetovic G, Samochowiec J, Roca Bennemar M, Becker T, Kurimay T, Gaebel W (2015a): EPA guidance on how to improve the image of psychiatry and of the psychiatrist. European Psychiatry 30 (3): 423-430.

Bhugra D, Ventriglio A, Kuzman MR, Ikkos G, Hermans MHM, Falkai P, Fiorillo A, Musalek M, Hoschl C, Dales J, Beezhold J, Rossler W, Racetovic G, Gaebel W (2015b): EPA guidance on the role and responsibilities of psychiatrists. European Psychiatry 30 (3): 417-422.

Bhugra D, Tasman A., Pathare S., Priebe S., Smith S., Torous J., Arbuckle M.R., Langford A., Alarcon R.D., Chiu H.F.K., First M.B., Kay J., Sunkel C., Thapar A., Udomratn P., Baingana F.K., Kestel D., Ng R.M.K., Patel A., De Picker L., McKenzie K.J., Moussaoui D., Muijen M., Bartlett P., Davison S., Exworthy T., Loza N., Rose D., Torales J., Brown M., Christensen H., Firth J., Keshavan M., Li A., Onnela J.-P., Wykes T., Elkholy H., Kalra G., Lovett K.F., Travis M.J., Ventriglio A. (2017): WPA-Lancet Psychiatry commission on the future of psychiatry. Lancet Psychiatry 4, 775-818.

Campion J, Bhui K S, Bhugra D (2012): European Psychiatry Association (EPA) Guidance on prevention of mental illness. European Psychiatry 27 (2): 68-80.

Carlile A, Bhugra D. (2013): Looking Ahead: Future of Mental Health Services: London: Mental Health Foundation

Kalra G, Christodoulou G, Jenkins R, Tsipas V, Christodoulou N, Lecic-Toveski D, Mezzich J, Bhugra D (2012): Mental health promotion: guidelines and strategies. European Psychiatry27 (2): 81-86.

Schouler-Ocak M, Graef-Calliess IT, Tarricone I, Qureshi A, Kastrup MC, Bhugra D (2015): EPA Guidance on cultural competence training. European Psychiatry 30 (3): 431-440. 